Images $\ln .$.

\title{
Disseminated histoplasmosis presenting with chronic ulcerative tongue lesions in a patient with diabetes
}

\author{
Mohamed Hadzri Hasmoni, ${ }^{1}$ Azarisman Shah Mohd Shah, ${ }^{1}$ Suhaimi Ayoub, ${ }^{2}$ Lau Shin Hin, ${ }^{3}$ \\ Mohd Amran Abd Rashid ${ }^{4}$
}

\author{
${ }^{1}$ Department of Internal Medicine, International Islamic University Malaysia, Kuantan, Malaysia \\ ${ }^{2}$ Kuantan Medical Center, Kuantan, Malaysia \\ ${ }^{3}$ Department of Oral Pathology and Medicine, Institute for Medical Research, Kuala Lumpur, Malaysia \\ ${ }^{4}$ Department of Radiology, International Islamic University Malaysia, Kuantan, Malaysia
}

Correspondence to Azarisman Shah Mohd Shah, risman1973@hotmail

\section{DESCRIPTION}

We describe a case of chronic tongue ulceration with systemic symptoms in a patient with poorly controlled diabetes. A biopsy of a lesion from the posterior third of the tongue showed features typical of histoplasmosis (figure 1). A CT of the thorax and abdomen revealed a diffuse reticulonodular pattern bilaterally (figure $2 \mathrm{~A}$ ). The intraabdominal organs were normal. A diagnosis of disseminated histoplasmosis was made. The patient was started on intravenous amphotericin B for 3 weeks followed by oral itraconazole $100 \mathrm{mg}$ twice a day for 1 month. A repeat CT thorax 6 weeks after antifungal treatment revealed resolution of the lesions (figure $2 \mathrm{~B}$ ).

Disseminated histoplasmosis refers to a process of severe fungus colonisation in the lungs and other organs and body sites ${ }^{1}$ The first ever case of disseminated histoplasmosis in a patient with diabetes living in a non-endemic area was reported in $1977 .^{2}$ Since the AIDS epidemic, disseminated histoplasmosis is more commonly seen. Chronic infection often presents with pancytopenia, hepatosplenomegaly,

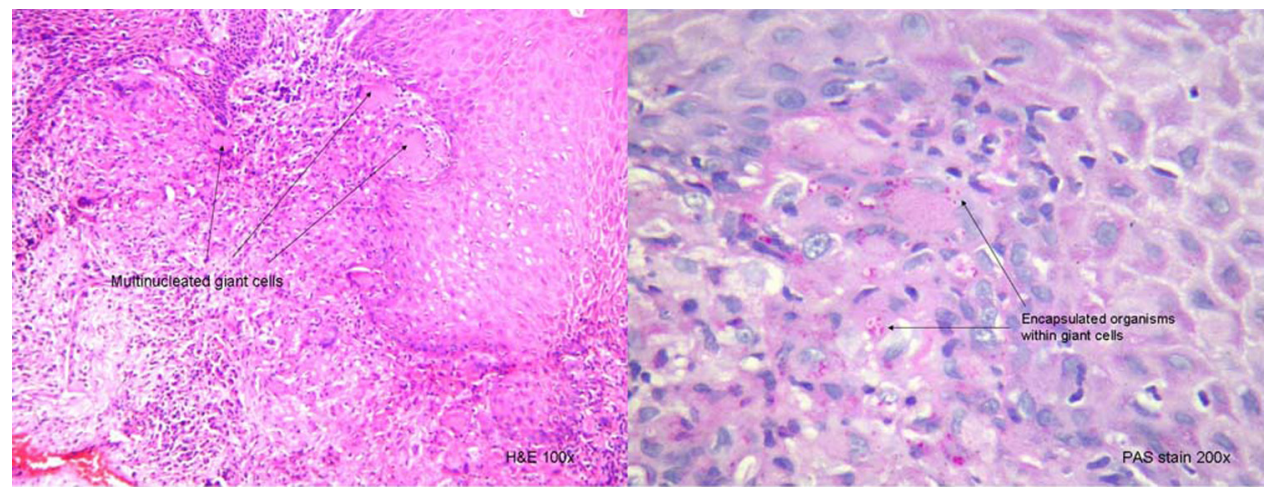

Figure 1 Tissue biopsy taken from the tongue lesion shows multinucleated giant cells containing encapsulated fungal organism.
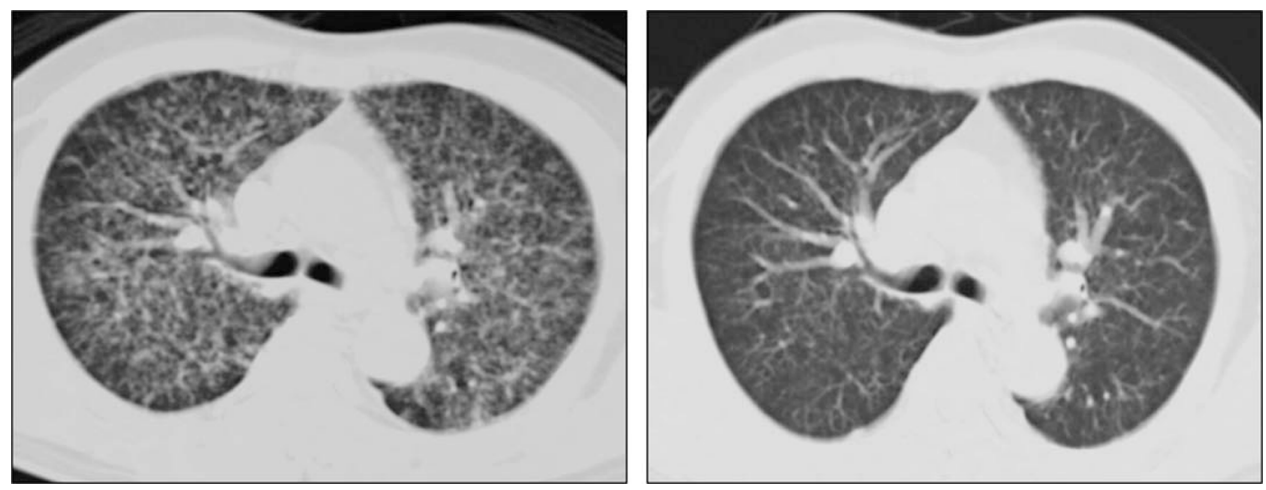

Figure 2 (A) CT of the thorax showing a diffuse reticulonodular pattern bilaterally which was more evident in the upper and middle zones. (B) CT of the thorax showing resolution of the reticulonodular shadowing 6 weeks after treatment. 


\section{BMJ Case Reports}

hepatitis and oropharyngeal or gastrointestinal lesions. ${ }^{3}$ A definitive diagnosis requires a positive blood culture or histological demonstration in involved tissue. ${ }^{3}$

\section{Learning points}

- Despite no obvious immunocompromise except for diabetes, a high suspicious of index is required to diagnose disseminated histoplasmosis.

- Recognition of the typical fungal infection is essential for a correct diagnosis.

- The finding of a diffuse reticulonodular pattern on CT of the thorax should be correlated with clinical presentation for accurate diagnosis and treatment.

\section{REFERENCES}

1. Deepe GS. Histoplasma capsulatum. In: Mandell GL, Bennet JE, Dolin R, eds. Principles and Practice of Infectious Diseases. Sixth edition. Philadelphia: Churchill Livingstone 2005:2718-33.

2. Jariwalla A, Tulloch BR, Fox H, et al. Disseminated histoplasmosis in an English patient with diabetes mellitus. Br Med J 1977;1:1002-4.

3. Goodwin RA Jr, Shapiro JL, Thurman GH, et al. Disseminated histoplasmosis: clinical and pathologic correlations. Medicine (Baltimore) 1980;59:1-33.

Competing interests None

Patient consent Obtained.

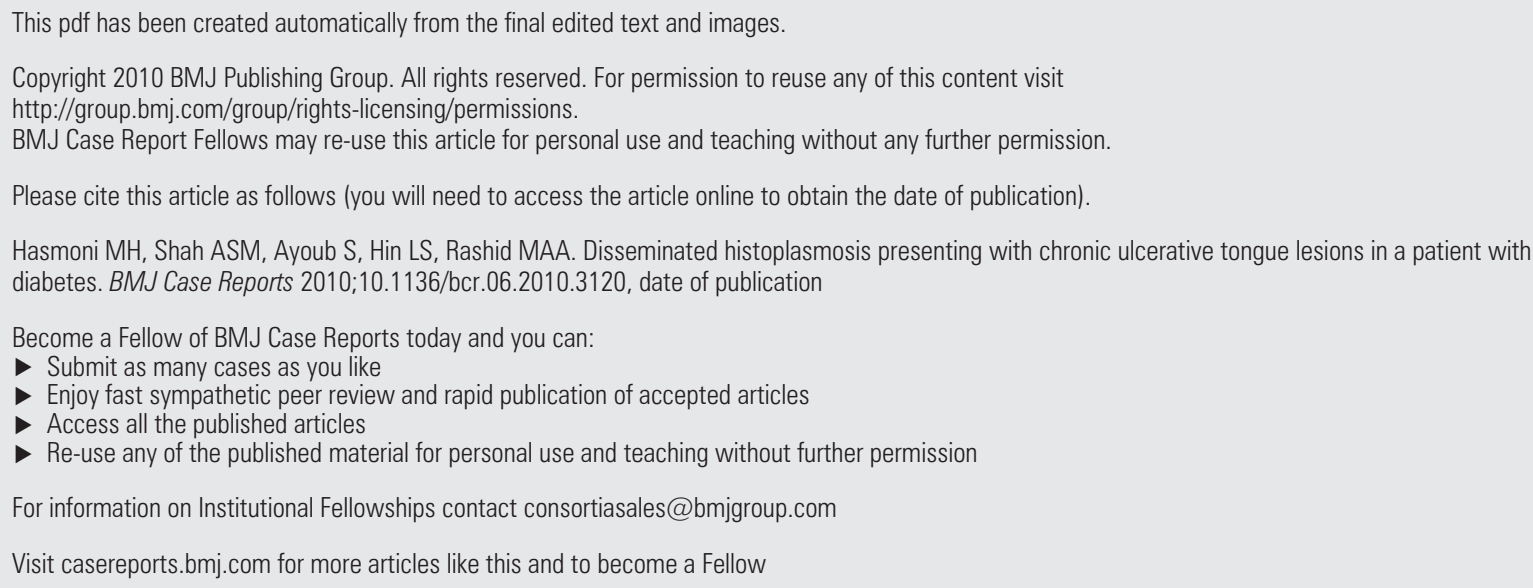

